\title{
Picture-story
}

\section{Body stalk anomaly}

\section{V C de Silva ${ }^{1}$, H Senanayake ${ }^{2}$ and K D V P Siriwardana ${ }^{3}$}

(Index words: Post-mortem findings, ultrasonography to avoid unnecessary caesarian section).

Body stalk anomaly is a severe body wall defect characterised by an absent or rudimentary umbilical cord, eventration of abdominal viscera, hindgut anomalies and severe skeletal deformities $(1,2,3)$. It is a rare sporadic condition with an incidence of $0.07 \%$ in live born infants (1).

Body stalk anomaly was seen in two neonates born at term, who died within one hour of birth. One was a spontaneous vaginal delivery, the other was delivered by emergency caesarian section. Prenatal sonography had not been done in both. The infants had absence of unbilical cord, eventration of liver and intestines, kyphoscoliosis, talipes equinovarus, imperforate anus and hypoplastic lungs, and were directly adherent to the placenta by their abdominal walls (Figure). One had hypoplastic left heart syndrome and a cystic right kidney. The other had indeterminate external genitalia with bilateral streak gonads.

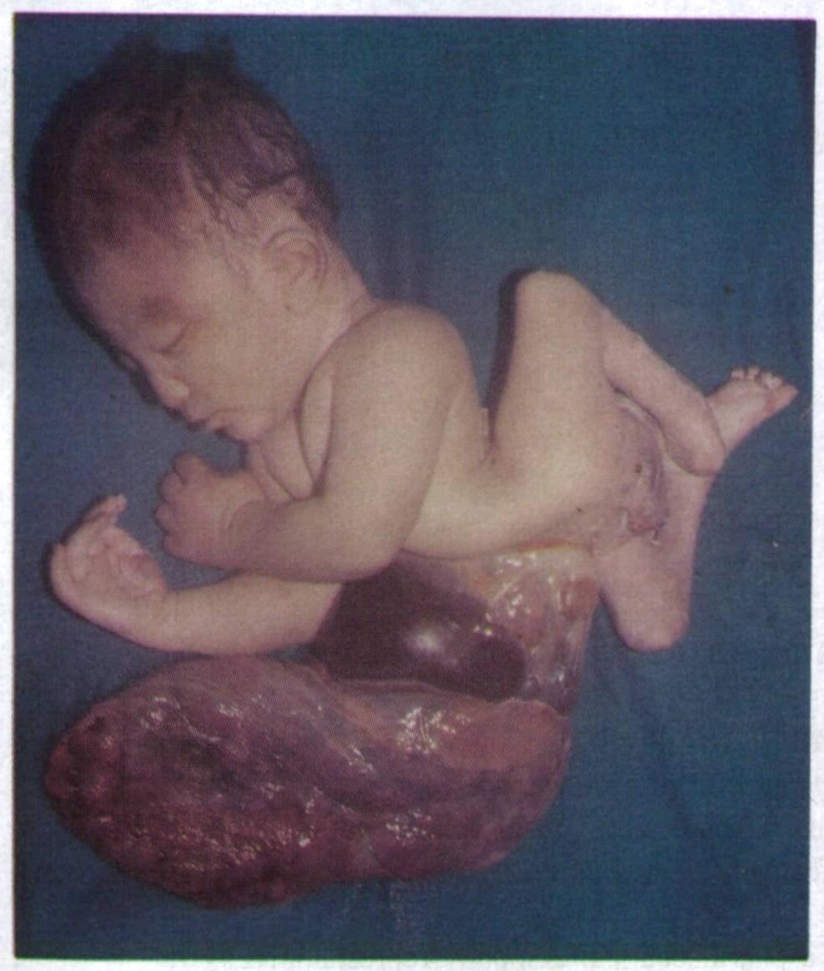

Figure. Body stalk anomaly. Eventration of abdominal viscera, and severe kyphoscoliosis.
The umbilical cord is derived from a small mass of mesoderm (body stalk), which attaches the embryo to the wall of the blastocyst. Abnormal development of the body stalk results in an absent or rudimentary umbilical cord. The fetus is directly attached to the placenta. Abdominal viscera lie in a sac outside the abdominal cavity covered by amnion (1). The karyotype is usually normal (4).

Prenatal ultrasonography will help to distinguish body stalk anomaly from omphalocoele and gastroschisis - two other conditions with eventration of abdominal viscera $(2,3,4,5)$. This is important because body stalk anomaly is uniformly fatal $(1,3)$, whereas the other two are not. The short umbilical cord may mimic cord compression and result in fetal distress, an indication for caesarian section (6). Prenatal diagnosis of body stalk anomaly will ensure avoidance of unnecessary caesarian section $(3,5)$.

\section{References}

1. Romero R, Ghidni A, Gabrielli S, Jeanty P. Gastrointestinal tract and abdominal wall defects. In: Brock DJH, Rodeck CH, FergusonSmith MA, eds. Prenatal Diagnosis and Screening. Edinburgh: Churchill Livingstone, 1992: 248.

2. Daskalakis G, Sebire NJ, Jurkovic D, Snijders RJ, Nicolaides KH. Body stalk anomaly at 10-14 weeks gestation. Ultrasound Obstetrics and Gynecology 1997; 10: 416-8.

3. Takeuchi K, Fujita I, Nakajima K, Kitagaki S, Koketu I. Body stalk anomaly: prenatal diagnosis. International Journal of Gynaecology and Obstetrics 1995; 51: 49-52.

4. Mann L, Ferguson-Smith MA, Desai M, Gibson AA, Raine PA. Prenatal assessment of anterior abdominal wall defects and their prognosis. Prenatal diagnosis 1984; 4: 427-35.

5. Nelison JP, Hood VD, Cupples W, Gibson AAM, Ferguson-Smith MA. Detection by ultrasound of abnormalities in twin pregnancies during the second trimester. British Journal of Obstetrics and Gynaecology 1982; 89: 1035-40.

6. Miller ME, Graham JM, Higginbottom MC, Smith DW. Compression-related defects from early amnion rupture: Evidence for mechanical teratogenesis. Journal of Pediatrics. 1981; 98: 292-7.

${ }^{1}$ Senior Lecturer, Department of Pathology, ${ }^{2}$ Senior Lecturer, Department of Obstetrics and Gynaecology, ${ }^{3}$ Research Assistant, Department of Pathology, Faculty of Medicine, University of Colombo. (Accepted 12 May 2001). 